\title{
Tecendo diálogo entre prática pedagógica e a identidade do educando da educação de jovens e adultos
}

\section{Weaving dialogue between pedagogical practice and the identity of the student of youth and adult education}

\author{
Karolaine Cristina Da Silva ${ }^{1}$ \\ Suzana Medeiros Batista Amorim²
}

\begin{abstract}
Resumo: A educação de jovens e adultos (EJA) trata-se de modalidade de ensino destinada a garantir os direitos educativos às pessoas que não tiveram oportunidade de estudar na idade considerada correta devido às implicações da vida. Neste viés, refletir a capacidade de transformar a vida dos indivíduos, a partir do espaço de educação formal, muito fortalece a discussão. As práticas pedagógicas desenvolvidas neste cenário da educação formal precisam ser acompanhadas, visando aprimoramento constantemente. Os desafios enfrentados neste contexto educacional são de variados aspectos no contexto educacional, como por exemplo, a falta de material didático; tempo para estudo dos discentes; necessidade de formação continuada dos professores atuantes neste campo da educação, entre outros. A prática pedagógica é considerada um dos pilares primordiais para a consolidação da construção da identidade social desse educando, reconhecendo suas especificidades e os empecilhos ao decorrer de seu percurso. Nesta direção, foi conduzido o presente estudo que buscou discutir os impactos das práticas docentes no desenvolvimento do discente da EJA em sua identidade. A pesquisa foi bibliográfica, de natureza qualitativa. Como fundamentação teórica, buscamos amparo nas visões dos estudiosos renomeados no assunto, como Nóvoa (2002), Paulo Freire (1987; 2013), Ciampa (1983), dentre outros que subsidiaram a elaboração do estudo. Esperase que este estudo possa contribuir com a reflexão da sociedade sobre a importância da EJA para a sociedade contemporânea.
\end{abstract}

Palavras-chave: Educação de Jovens e Adultos; Identidade; Prática docente.

\footnotetext{
${ }^{1}$ Graduanda do Curso de Pedagogia, Universidade de Vassouras- RJ.E-mail: karolmanu2801@ gmail.com

2 Doutora em Educação (2021) e Mestre em Educação (2011) pela Universidade Estácio de Sá- RJ; Professora do Curso de Pedagogia da Universidade de Vassouras-RJ. E-mail: suzana-amorim@uol.com.br.
}

Recebido em 23/01/2022

Aprovado em 10/02/2022

Sistema de Avaliação: Double Blind Review

OPEN ACCESS 
Abstract: Youth and adult education (EJA) is a teaching modality aimed at guaranteeing educational rights to people who did not have the opportunity to study at the age considered correct due to the implications of life. In this bias, reflecting the ability to transform the lives of individuals, from the space of formal education, greatly strengthens the discussion. The pedagogical practices developed in this scenario of formal education need to be monitored, aiming for constant improvement. The challenges faced in this educational context are of various aspects in the educational context, such as the lack of teaching material; time for students to study; need for continuing education of teachers working in this field of education, among others. The pedagogical practice is considered one of the main pillars for consolidating the construction of this student's social identity, recognizing their specificities and obstacles along their path. In this direction, this study was conducted, which sought to discuss the impacts of teaching practices on the development of EJA students in their identity. The research was bibliographical, of a qualitative nature. As a theoretical foundation, we seek support in the views of renowned scholars on the subject, such as Nóvoa (2002), Paulo Freire (1987; 2013), Ciampa (1983), among others who supported the elaboration of the study. It is hoped that this study can contribute to society's reflection on the importance of EJA for contemporary society.

Keywords: Youth and Adult Education; Identity; Teaching practice.

\section{Introdução}

No percurso histórico da Educação de Jovens e Adultos (EJA) nos deparamos com discussões sobre a colonização do Brasil, em 1.500 com a chegada dos Jesuítas e a família real (STRELHOW, 2010). No caminhar foram agregados momentos que transformaram, de forma singela, a EJA no país. A modalidade da EJA no país é marcada por políticas públicas insuficientes (MIRANDA, SOUZA E PEREIRA, 2016).

Nesta perspectiva, Rocha e Souza (2013) ressaltam que a EJA foi criada para reparar dívida social antiga do Estado Brasileiro, denunciada desde os anos de 1930, junto aos cidadãos que, quando crianças, não tiveram acesso e domínio da leitura e escrita, assim como aos códigos matemáticos. Ser podado deste direito é de fato a perda de um instrumento imprescindível para presença significativa na convivência social contemporânea e, especialmente, para a superação das desigualdades sociais. Ribeiro e Novais (2019) apontam que a alfabetização de adultos tem espaço no Brasil objetivando erradicar o analfabetismo.

Atualmente, o ensino da EJA encontra-se em constante desafio devido à evasão escolar que atinge essa clientela da sociedade brasileira. É importante destacar que o método de ensino utilizado em sala de aula está devidamente ligado ao educando e seus resultados. Infelizmente, ainda, na EJA são utilizadas metodologias infantilizadas, o que gera um 
distanciamento pedagógico significativo. Diante disso, é importante ressaltar que devemos tratar os educando da EJA de acordo com as suas respectivas idades e oportunizar espaços para trabalhar a amplitude de conhecimento adquirida por cada um (FERNANDES; OLIVEIRA, 2020).

Shiroma e Lima Filho (2011, p. 727) salientam que "[...] historicamente, em nosso país, as políticas educacionais não favoreceram que alunos das classes trabalhadoras realizassem um percurso educacional capaz de garantir o direito à conclusão da educação básica com formação integral”. A educação é direito de todos os seres humanos, mas na realidade o ensino não ocorre de forma igualitária. É de fundamental importância à preocupação de novas maneiras de atender as necessidades do público da Educação de Jovens e Adultos, tanto na parte curricular como na estrutura e na escolha dos recursos que serão utilizados para atendê-los. A preocupação com esse público e recursos pedagógicos que com eles são trabalhados busca apresentar conteúdos ligados à faixa etária dos alunos e ligados a realidade, proporcionando uma educação de qualidade, diferenciada, participativa e com um currículo voltado para atividades exclusivas para a EJA.

Novo e Mota destacam que "[...] é preciso que a sociedade compreenda que alunos da educação de jovens e adultos vivenciam problemas como preconceito, vergonha, discriminação, críticas dentre tantos outros". E que tais questões são vivenciadas tanto no cotidiano familiar como na vida em comunidade.

Entre diversos aspectos discutidos na busca do fortalecimento da modalidade de ensino em questão, deparamo-nos com as práticas pedagógicas docentes desenvolvidas nas salas de aula da EJA. Nesta perspectiva, a Educação de Jovens e Adultos necessita ser pensada de fato para sua clientela. Com base nas Diretrizes Curriculares Nacionais da Educação de Jovens e Adultos (Brasil) “[...] os alunos da EJA são diferentes dos alunos presentes nos anos adequados à faixa etária. São jovens e adultos, muitos deles trabalhadores, [...] com expectativa de (re)inserção no mercado de trabalho e com um olhar diferenciado".

Nesta direção, o presente estudo buscou discutir os impactos das práticas docentes no desenvolvimento do discente da EJA em sua identidade. Tendo em vista que a presente pesquisa se propôs realizar um estudo bibliográfico como instrumento de investigação e sendo esta modalidade de pesquisa aplicada ao objeto de análise apresentado, que se inclui em nosso objetivo desenvolvido para o trabalho, inferimos que o estudo se traduziu em uma investigação de natureza qualitativa. Trata-se de uma pesquisa de abordagem qualitativa, a qual 
se preocupa com aspectos da realidade que não podem ser quantificados (SILVEIRA, CÓRDOVA, 2009).

A pesquisa passou pelas seguintes etapas, a saber: primeiro foi realizado levantamento de material teórico, como, exemplo, textos que discutem o tema, considerando a atualização dos mesmos e a vida profissional dos autores. Valorizaram- se, também, os documentos mais recentes, além de utilizar os textos clássicos de autores renomados dentro da temática estudada; a partir deste levantamento geral, selecionamos os que observarmos possuir íntima relação com o objeto de estudo; identificadas possíveis linhas de composição com nosso trabalho, nos debruçaremos na leitura em profundidade, de maneira a organizar os temas que foram abordados em nossa pesquisa; com as partes teóricas selecionadas e organizadas, passamos a redigir este artigo, de forma a articular as questões teóricas e o resultado da coleta de dados, realizando um contraponto.

\section{Prática Pedagógica na EJA}

A educação de jovens e adultos possui especificidades ligadas ao seu público, devendo ser propostas em suas aulas práticas pedagógicas apropriadas a tal modalidade, necessitando de flexibilização, visto ser de extrema importância considerar as condições de vida de cada educando. Os trabalhos pedagógicos desenvolvidos na EJA contribuem na formação dos discentes socialmente ativos e capazes de se intitular como sujeitos responsáveis por suas próprias escolhas, sendo identificados como os formadores de suas histórias de vida.

A educação não deve ser um depósito de conteúdo, pois tendo em vista que aprendemos compartilhando e trocando experiências de nossas práticas cotidianas (FREIRE, 2013). Somos constituídos por inúmeros processos para a adequação de novas práticas, e assim compor um cenário para a educação brasileira que seja marcada pela importância do homem como sujeito de sua própria formação. Paulo Freire (2013) destaca a pertinência de estabelecer elos entre sonhos e realidades e a necessidade de que a educação seja efetivada através da memória e consciência crítica. O professor vai além do simples ato de educar e parte do princípio que o mesmo traz consigo suas experiências ao decorrer de sua formação acadêmica.

Amorim e Duques (2017, p. 232) salientam que "professores da EJA requerem um conhecimento diferenciado, pois estão em contato com um tipo diferente de aluno no que diz 
respeito ao perfil, necessidades, interesses e situações de vida". O perfil desse professor atuante na EJA necessita de ser construído com as especificidades da modalidade de ensino.

Di Pierro (2003) destaca que

[...] os docentes que atuam com os jovens e adultos são, em geral, os mesmos do ensino regular. Ou eles tentam adaptar a metodologia a este público específico, ou reproduzem com os jovens e adultos a mesma dinâmica de ensino-aprendizagem que estabelecem com crianças e adolescentes. (DI PIERRO, 2003, p. 17).

A EJA por muitos anos teve seu ensino de forma infantilizada, necessitando assim de um modelo pedagógico condizente com as características de seu alunado por meio de sua vivência, valorizando os conhecimentos prévios e suas experiências, possibilitando autonomia e inserção perante a sociedade.

Furlanetti (2009) destaca que

[...] as necessidades de se aprender a ler e a escrever inicialmente dos nossos educandos estão situadas dentro das necessidades mais imediatas do uso mais prático do conhecimento, que sua condição de leitor e escritor lhe permite. Entretanto, não podemos pensar que isso bastará para que nossos educandos sejam leitores e escritores, se faz necessário desenvolver atividades que desenvolvam as suas habilidades de leitores e escritores para que sejam desafiados a buscar informações para melhor compreensão do mundo. (FURLANETTI, 2009, p. 22).

A formação continuada do professor é essencial para o desenvolvimento das boas práticas pedagógicas na EJA. Para Freire (2013, p. 58) "ninguém nasce educador ou marcado para ser educador. A gente se faz educador, a gente se forma, como educador, permanentemente, na prática e na reflexão da prática”.

A formação continuada do professor possibilita que as práticas docentes estejam alicerçadas em fazeres pedagógicos significativos. Amorim e Duques (2017) afirmam que

[...] no contexto da Educação de Jovens e Adultos, em que os educadores precisam reconfigurar sua atuação em face das demandas do universo da modalidade, tomar a prática docente reflexiva como um caminho a ser percorrido desde o início da formação parece uma boa alternativa para assegurar processos formativos sólidos. (AMORIM E DUQUES, 2017, p. 233).

Os processos de formação dos docentes para a apropriação e validação de metodologias, frutos de reflexão teórica, mas também vivenciados pela sua experiencialização são produtos de um percurso formativo. Subsidiadas neste cenário as aulas propostas estarão 
com bom planejamento pedagógico, que de forma efetiva auxilia na construção do conhecimento do educando.

É importante salientar que o educando da EJA carrega consigo seus conhecimentos de mundo e práticas repletas de saberes variados tornando-se possível, por meio dessa troca do aluno e com o professor, construir conhecimento de forma intencional e favorável, sendo o educador peça chave na mediação das competências para a evolução desse processo de formal pessoal.

Compreender os desafios que abarcam a EJA ao decorrer de todo o seu percurso de existência, contribuindo para a reformulação do currículo apresentado, uma vez que são inúmeras as dificuldades dos docentes. É importante considerar quem é esse educador da EJA e como o seu trabalho será elaborado, pois estamos discutindo sobre alunos que necessitam de uma educação emancipadora, sendo capaz de construir um olhar crítico através da realidade vivida.

Em relação à educação continuada, novamente, somos levados a considerar sua necessidade e como os professores estão sendo preparados para enfrentar as salas de aula, uma vez que o conhecimento e as práticas pedagógicas acabam deixando de ser desmembrados e os recursos de novas tecnologias são pouco utilizados. Tal cenário tem sofrido alterações, visto que com a pandemia do COVID-19 o uso das ferramentas digitais foi intensificado nas práticas pedagógicas na educação formal.

$\mathrm{O}$ ato de educar não é uma junção de conhecimentos acumulativa, é necessário que esse educador acredite no potencial de cada aluno almejando a efetivação de um ensino de qualidade (FREIRE, 2013). É notório que os professores da EJA necessitam de construção de conhecimentos diferenciada dos demais professores, pois primeiramente devem ter em pauta qual a realidade e necessidade do programa, bem como ter mente que a EJA é constituída por perfis de jovens e adultos que voltam às escolas com diferentes intuitos e objetivos, assim sendo necessário orientar o trabalho pedagógico para a construção planejada voltada para o sua clientela e construir cenários que sejam utilizados em seu cotidiano escolar.

Diante das circunstâncias da educação brasileira, a mesma necessita de novos caminhos, já que as metodologias e os recursos estão sendo insuficientes para as transformações pré-estabelecidas. A EJA deve ser responsável por cidadãos que exerçam um olhar crítico, capazes de dialogar sobre suas opiniões, executar seu papel enquanto sujeito e usufruir de todo o direito que o mundo letrado é capaz de oferecer. 
É importante salientar que não há prática pedagógica sem reflexão crítica do trabalho docente, no qual o educador deve estar sempre atualizado de novos meios e recursos para a efetivação de suas aulas, construindo conhecimentos e caminhos que se tornam fonte de pesquisa para outros educadores. Segundo Pimenta e Lima (2012, p. 51) “[...] o professor pode produzir conhecimento a partir da prática, desde que na investigação reflita intencionalmente sobre ela, problematizando os resultados obtidos com o suporte da teoria. E, portanto, como pesquisador de sua própria prática".

\section{Construção Identitária do Discente da EJA}

O homem é composto por cultura e história. Através de cada ser humano existem inúmeras particularidades que caracterizam a trajetória de cada um de nós. Ao abordamos o conceito de identidade devemos considerar que a mesma não é constituída temporariamente. Para Ciampa (2007, p. 137) "[...] identidade é o reconhecimento de que é o próprio de quem se trata; é aquilo que prova ser uma pessoa determinada, e não outra". Caracterizar a identidade é saber diferenciar as igualdades e diferenças, já que somos constituídos por aspectos que ligeiramente pode nos igualar ou diferenciar.

Ciampa (1984) destaca que somos constituídos por inúmeras personalidades, sendo elas utilizadas em ambientes ou situações diversas. O autor (1984, p. 61) ainda, salienta que somos "uma totalidade contraditória, múltipla e mutável, no entanto uma". Assim, podemos entender que o ser humano é composto por variações de quem são.

Pacheco e Ciampa (2006) caracterizam a identidade como uma metamorfose correlacionada a um fenômeno social e não natural, já que sofremos interferências desde quando nascemos até a morte. Nesse sentido, refletir sobre a constituição de quem são os alunos que frequentam a EJA, implica em analisar a caracterização da educação como agente transformador capaz de tornar tais indivíduos, sujeitos de sua própria formação. A partir da ideologia de cada indivíduo encontramos uma totalidade de cada um de nós, que em diversos momentos da vida é enfatizado por variações de nós mesmos que constituem a ampla identidade e construção do nosso eu.

Falar do educando da EJA é discutir através do âmbito escolar trajetórias e memórias construídas no decorrer da vida desse estudante, cabendo a nós educadores conhecer de maneira mais abrangente esses jovens e adultos. Novos tempos e novos saberes têm sido 
exigidos frente à educação formal na sociedade contemporânea. Neste contexto, torna-se necessário refletir, constantemente, como podemos nos adaptar a esse novo cenário educacional oriundo da pandemia do COVID- 19.

A Educação de Jovens e Adultos requer muita atenção, visto ser caracterizada a partir de seus sujeitos (jovens e adultos), do seu ambiente escolar, das suas especificidades que variam de comunidade para comunidade e perpassando pela questão do acolhimento, a prática pedagógica, que se faz necessariamente ser diferenciada.

Ferreira e Sasso (2013, p. 85) afirmam que "um dos desafios da EJA é o de problematizar estas identidades e diferenças, questionar a diversidade de culturas, indagar se se trata da multiculturalidade de fato, ou apenas reproduz-se a cultura dominante, que se mantém homogeneizando as demais culturas".

Cabe ao professor, diante da pluralidade de sujeitos que estão em uma única sala de aula, o que faz com que a educação aconteça a partir da realidade social do aluno e com seus determinantes sobre seu modo de vida, procurar transformar o conhecimento acumulado em saberes que tragam aos alunos o entendimento de sua realidade.

Nòvoa (1992) afirma que

[...] a identidade não é um dado adquirido, não é propriedade, não é produto. A identidade é um lugar de lutas e de conflitos, é um espaço de construção de maneiras de ser e de estar na profissão. Por isso, é mais adequado falar em processo identitário, realmente a mescla dinâmica que caracteriza a maneira como cada um se sente e se diz professor [...]. A maneira como cada um de nós ensina está diretamente dependente daquilo que somos como pessoa quando exercemos o ensino. (NÓVOA, 1992, p. 16-17).

A identidade é construída ao longo do percurso da vida do ser humano. Pimenta e Lima (2009, p.112) nos falam que: "a identidade se constrói com base no confronto entre as teorias e as práticas, na análise sistemática das práticas à luz das teorias [...]”. A partir da ideia que abarca a função social da EJA, podemos compreender que os educandos caracterizam-se através de suas relações sociais e a convivência com o meio em que estão inseridos.

O âmbito de origem e sua bagagem de vida são de extrema relevância, já que são constituídos por uma diversidade de elementos agregados fora da esfera escolar. A educação de jovens e adultos vai além do simples fato de ensinar a ler e escrever, estamos discutindo sobre a formação de quem são esses alunos e quais os seus valores durante todo o percurso escolar. Para Antonio e Amorim (2018, p. 75) “[...] a função social da escola é modificar a 
sociedade por meio dos saberes nela construídos, a mesma não pode negar-se a discutir as questões do mundo e tão pouco selecionar esta ou aquela discussão de acordo com os interesses de determinados grupos sociais".

O cenário educacional deve ser efetivo e os alunos autônomos de suas práticas, principalmente do seu pensar, para assim ter ações significativas que de fato contribuirá com sua construção como sujeito. Ensinar não é apenas transmitir conhecimentos, mas sim possibilitar caminhos e espaços para a construção do conhecimento, criando assim caminhos para esse conhecimento ser significativo e conscientizar o papel de cada indivíduo que será efetivado ao longo de cada cenário. (FREIRE, 2013).

A maneira de educar está diretamente ligada ao engajamento de cada aluno, encorajando e possibilitando que os mesmos encontrem seus objetivos através do processo de formar sujeitos reflexivos e ativos socialmente. Conhecer a formação identitária desse aluno é considerar os fatores que o levou a chegar até o dia de hoje, o caminho percorrido sua identificação.

\section{Considerações finais}

Quando falamos do efeito da prática docente na construção da identidade do educando da EJA, temos que levar em conta todo o percurso construído durante a trajetória de sua vida, já que somos formados por nossas particularidades. Através da evolução da educação de jovens e adultos, o ensino deve considerar não só a construção desse discente, mas a sua trajetória, permitindo conhecer suas identidades e interessar-se pela necessidade de cada um.

O aprendizado deve ultrapassar as barreiras da sala de aula e tornar-se notório na vida de cada educando, seja ele criança, jovem ou adulto. Nesse processo o estudante é capaz de concretizar conhecimentos através das metodologias propostas por seu educador e conhecer novos significados para inúmeras situações cotidianas, sendo assim, possível exercer sua cidadania com propriedade.

Diante do exposto, vimos a importância de dialogar sobre os impactos das práticas docentes no desenvolvimento pedagógico do discente da Educação de Jovens e Adultos, uma vez que o professor torna-se um facilitador do conhecimento, capaz de construir uma ponte para o desenvolvimento pessoal de cada educando. O professor da EJA necessita propor uma metodologia que tente resgatar a cidadania de cada sujeito, sem deixar de tornar plausíveis as

\section{.}


concepções de vida adquiridas ao decorrer de sua trajetória, mesmo que sejam obtidas de modo informal.

Dessa forma, refletir sobre como as práticas pedagógicas docentes desenvolvidas na EJA contribuem na formação da identidade desses educandos, enquanto sujeitos sociais vão além da necessidade de reparar uma dívida histórica, uma vez que a população não alfabetizada não consegue obter uma leitura clara da sociedade em que vive. Portanto, com a concretização desse trabalho, percebemos que o professor deve estar preparado para atuar na EJA e assim obter uma prática pedagógica que atenda a sua clientela, não de uma forma breve e superficial.

O docente que deseja atuar nesse segmento deve compreender que trabalhar com a EJA é estar disposto a buscar e elaborar novos meios de conhecimento, já que essa clientela não obteve a oportunidade de estudar na idade considerada ideal deixando de fazer uma leitura clara da sociedade em que vive. É inegável a importância da autonomia do educando da Educação de Jovens e Adultos no processo de construção de sua identidade, pois, como vimos, a identidade é fragmentada, perpassa variadas transformações de si para chegar até o que somos hoje.

Para que a identidade se desenvolva é necessário compreender o processo no qual o sujeito passou para determinar o seu “eu”. Na análise da história de vida de cada educando observamos que são inúmeros os desafios encontrados para a reinserção escolar, seja pela idade, falta de alimentação ou os estereótipos que abarcam essa modalidade de ensino.

Findando este estudo, entendemos a necessidade de novas pesquisas sobre os aspectos que envolvem a identidade dos atores da Educação de Jovens e Adultos, uma vez que muito ainda precisamos fortalecer as práticas docentes e discentes da EJA no campo da educação formal. Por hora, esperamos ter contribuído com as discussões sobre a temática proposta.

\section{Referências}

AMORIM, Antonio; DUQUES, Maria Luiza Ferreira. Formação de educadores de EJA: caminhos inovadores da prática docente. Revista Educação. Porto Alegre, v. 40, n. 2, p. 228 239, maio-ago. 2017.

ANTONIO, Janinne da Silva; AMORIM, Suzana Medeiros Batista Amorim. Função social da escola: a metamorfose que precisamos. In: RICCI, Adiel Queiroz; MONTEIRO, Ângelo Ferreira; CAVALCANTE, Irenilda Reinalda Barreto de Rangel Moreira, et al.(Orgs.) 


\section{ISSN 1809-1628

Formação em pedagogia no Brasil do século $\mathbf{X X}$ - desafios, propostas e caminhos.

Vassouras: Universidade de Vassouras, 2018.

CIAMPA, Antonio da Costa. A estória do Severino e a história da Severina. um ensaio de psicologia social. São Paulo: Brasiliense, 1983.

CIAMPA, Antonio da Costa. Identidade. In: CODO, W.; LANE, S. T. M. (Orgs.). Psicologia social: o homem em movimento. São Paulo: Brasiliense, 1984. p. 58-75.

CIAMPA, Antonio da Costa. Políticas de identidade e identidades políticas. In: DUNKER, C. I. L.; PASSOS, M. C. (Orgs.). Uma psicologia que se interroga: ensaios. São Paulo: Edicon, 2002, p. 133-144.

DI PIERRO, Maria Clara. Seis anos de Jovens e Adultos no Brasil: os compromissos e a realidade, São Paulo: Ação Educativa, 2003.

FERNANDES, Ana Paula Cunha dos Santos; OLIVEIRA, Iranildo da Silva. Evasão na EJA: um desafio histórico. Revista Educação \& Formação, 2020. Acesso em: 28 mar. 2021.

FERREIRA, Aline Coelho; SASSO, Raquel Andrade. Vida em folhas de papel: os cadernosdiário na educação de jovens e adultos do município de Florianópolis. EJA EM DEBATE, Florianópolis, ano 2, n. 3. dez. 2013. Disponível em: https://periodicos.ifsc.edu.br/index.php/EJA/issue/view/33. Acesso em: 30 out. 2021.

FREIRE, Paulo. Pedagogia da autonomia - saberes necessários à prática educativa. São Paulo: Paz e Terra, 2013.

FREIRE, Paulo. Pedagogia do oprimido. 17. ed. Rio de Janeiro: Paz e Terra, 1987.

FURLANETTI, Maria Peregrina de Fátima Rotta. Compartilhando Experiências, dialogando com a prática da alfabetização. $1^{a}$ Edição, Canal 6, SP, 2009. Disponível em: http://docs.fct.unesp.br/grupos/gepep/livro_fatima.pdf. Acesso em: 01 nov. 2021

MIRANDA, Leila Conceição de Paula; SOUZA, Leonardo Tavares de; PEREIRA, Isabella Rodrigues Diamantino. A trajetória histórica da EJA no Brasil e suas perspectivas na atualidade. SEMINÁRIO DE INICIAÇÃO CIENTÍFICA, 2016, Montes Claros. Disponível em: https://www.ifnmg.edu.br/arquivos/2016/proppi/sic/resumos/e4e0c388-a72445cb-8189-46e3a70afa64.pdf. Acesso em: 28 mar. 2021.

NOVO, Benigno Núñez; MOTA, Antonio Rosembergue Pinheiro e. O professor de educação de jovens e adultos. 2019. Disponível em: https://jus.com.br/artigos/74536/oprofessor-de-educacao-de-jovens-e-adultos. Acesso em: 02 nov. 2021.

NÓVOA, Antônio. Vida de professores. Porto: Porto Editora, 1992.

PIMENTA, Selma Garrido; GHEDIN, Evandro (Org.). Professor reflexivo no Brasil: gênese e crítica de um conceito. 7. ed. São Paulo: Cortez, 2012. 


\section{REVISTA MULTIDISCIPLINAR}

PIMENTA, Selma Garrido; LIMA, Maria Socorro Lucena. Estágio e Docência: questões e propostas. $4^{\mathrm{a}}$ São Paulo: Cortez, 2009.

RIBEIRO, Poliane; NOVAIS, Valéria Silva de Moraes. A juvenilização na educação de jovens e adultos no Brasil e no Amapá. In: DIAS, Alder de Souza; GUIMARÃES, André Rodrigues; NOVAIS, Valéria Silva de Moraes (Orgs). Pensamento freiriano e educação de jovens e adultos na Amazônia. 1. ed. Curitiba: Appris, 2019.

ROCHA, Raquel da Silva; SOUZA, Solange Gois de. Prática de alfabetização na educação de jovens e adultos. São Paulo: Cortez, 2013.

SILVEIRA, Denise Tolfo; CÓRDOVA, Fernanda Peixoto. A pesquisa científica. In: GERHARDT, Tatiana Engel; SILVEIRA, Denise Tolfo. (Org.) Métodos de pesquisa. Porto Alegre: Editora da UFRGS, 2009.

SHIROMA, Eneida Oto; LIMA FILHO, Domingos Leite. Trabalho docente na Educação Profissional e Tecnológica e no PROEJA. Educação \& Sociedade, Campinas, v. 32, n. 116, 2011.

STRELHOW, Thyeles Borcarte. Breve história sobre a educação de jovens e adultos no Brasil. Revista HISTEDBR On-line, n. 38, p. 49-59, Campinas, jun.2010. 